\title{
Alumni survey for University of Manitoba DEPARTMENT OF BIOSYSTEMS ENGINEERING
}

\author{
M.L. Mackie and D.D. Mann \\ Department of Biosystems Engineering, University of Manitoba, Winnipeg, MB R3T 5V6 \\ Corresponding Author: Danny.Mann@umanitoba.ca
}

\begin{abstract}
This paper presents the results of a survey of 61 alumni from the University of Manitoba Department of Biosystems Engineering. A three-section survey was developed to evaluate 12 attributes outlined by the Canadian Engineering Accreditation Board. The survey requested that alumni assess the 12 attributes in three ways: the importance of each attribute in their current employment, the level of preparedness they had received in each attribute from their education in the Biosystems Engineering program, and the competency level required in each attribute by their current employment. Using gap analysis, the level of preparedness received by Biosystems Engineering alumni was compared with level of competency required in current employment. The level of preparedness exceeded competency required on 10 of 12 attributes; only attributes of "communication" and "impact of engineering on society and the environment" were found to be deficient using this analysis. Comparison of the importance of attributes to level of preparedness showed that level of preparedness is meeting industry expectations on attributes of "knowledge base for engineering", "design”, "use of engineering tools" with room for improvement on "problem analysis", "investigation" and most of the soft skill attributes. Interestingly, alumni who had participated on an extra-curricular team rated their preparedness on "team work" and "communication skills" lower than the overall response even though these extra-curricular activities provide real-life experience with these attributes.
\end{abstract}

Keywords: Graduate attributes, Alumni survey, Industry preparedness

\section{INTRODUCTION}

Current engineering accreditation requirements in Canada include assessment of graduates according to specified graduate attributes. The University of Manitoba has developed a strategy that involves both direct assessment of Canadian Engineering Accreditation Board (CEAB) graduate attributes (i.e., performance in coursework) and indirect assessment of graduate attributes. These indirect methods include co-op surveys, industry forums, exit surveys, end-of-course surveys, student forums, and alumni surveys. It is anticipated that collection of data from these multiple sources will enable sound conclusions to be drawn. The specific purpose of this paper is to describe an alumni survey that was completed for the Biosystems Engineering program at the University of Manitoba in the fall of 2013.

The survey was designed to evaluate the $12 \mathrm{CEAB}$ graduate attributes [1] in relation to i) importance of the attribute to the alumni's current employment, ii) the level of preparedness that the alumni received by the Biosystems Engineering program, and iii) the competency level required by their employment. A total of 61 alumni completed the survey, with a large portion of respondents graduating within the last 5 years. Preliminary analysis of the data has been completed with the intent of trying to identify whether gaps exist between level of academic preparation and level required by employment.

It is important to note that the results of this alumni study should not be considered in isolation. This alumni study is just one of several tools that is being used to indirectly assess the performance of graduates of the Biosystems Engineering program at the University of Manitoba. No attempt to correlate information from the various indirect assessment tools has occurred. This paper will refrain from stating overall conclusions about the Biosystems Engineering program.

\section{RESEARCH METHODOLOGY}

\subsection{Target Population}

The University of Manitoba Department of Biosystems Engineering alumni were the target population for this study. There are 388 alumni of the department, however, valid email addresses were available for only 221 of them.

\subsection{Survey Instrument}

The alumni survey consisted of 36 questions divided into 3 sections. The first section consisted of 12 questions that provided demographic data about the survey 
respondent. The second section of the survey consisted of 20 questions that asked alumni to evaluate the $12 \mathrm{CEAB}$ graduate attributes relative to i) importance of the attribute to the alumni's current employment, ii) the level of preparedness that the alumni received by the Biosystems Engineering program, and iii) the level of competency required in each attribute by their employment. Importance of the attribute was rated on a scale of 1 to 5 with 1 being unimportant and 5 being extremely important. Level of preparedness was also rated on a scale of 1 to 5 with 1 being unprepared and 5 being extremely prepared. Finally, competency level required by current employment was assessed according to the six levels of Bloom's taxonomy (i.e., knowledge, comprehension, application, analysis, synthesis, and evaluation). Numerically, these were coded as 1 through 6 , respectively. The third section of the survey consisted of 4 questions about the alumni's professional development. The survey received ethics approval from the University of Manitoba Research Ethics Board.

\subsection{Survey Procedure}

The survey was implemented using an online survey tool (SurveyMonkey). To recruit participants, an email with departmental letterhead, an invitation to participate in the survey, a link to the online survey, information on how to obtain results, and contact information (for the Human Ethics and Research Board, the principal investigator and project advisor) was distributed. A trial survey was initially distributed to 10 participants to ensure proper functioning of the software and to determine that the desired analysis could be conducted with the planned survey structure. The respondents that replied to the trial survey were also included in the survey results because no changes were made to the survey questions as a result of the trial survey. Following the trial survey, the survey was distributed to the target population through email. The online survey software collected and stored alumni responses for subsequent analysis. The software also provides basic analysis of questions and permits transfer of raw data for further analysis.

\section{RESULTS AND DISCUSSION}

\subsection{Respondent Demographics}

The survey received 61 responses from the 221 individuals contacted giving a response rate of $27.6 \%$. Nulty [2] reported that the required response rate using liberal conditions is $8-10 \%$. According to the criterion presented by Nulty [2], the results of this survey are significant and can be used for identifying areas for curriculum development.
Year of graduation is important information for trend analysis. The data relating to alumni's year of graduation are shown in Figure 1. Of the 61 respondents, 24 (39\%) graduated within the last 5 years providing a good basis for discussion of the current Biosystems Engineering curriculum. Only 7 of the respondents were over the age of 50 . Of the 61 respondents, only $22 \%$ had participated in co-operative education during their undergraduate studies. Similarly, only $26 \%$ of survey respondents had participated in an extra-curricular design team during their undergraduate studies.

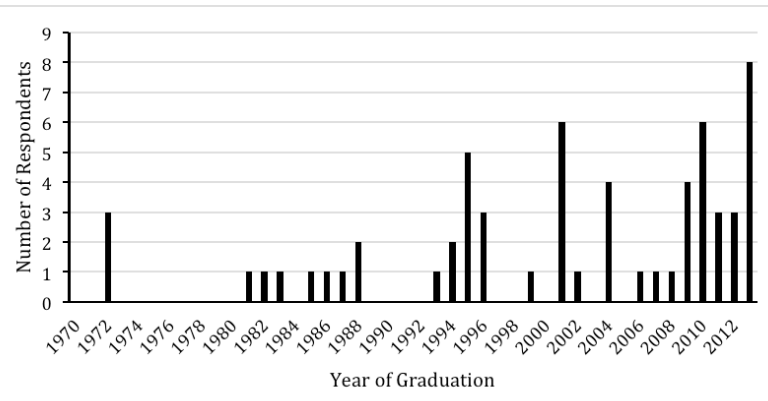

Figure 1. Respondent's year of graduation from the Biosystems Engineering program.

\subsection{Importance of Attributes to Current Employment}

Alumni were asked to rate each of the 12 CEAB graduate attributes based on importance to their current employment using one of these 5 descriptors: unimportant, somewhat important, important, very important and extremely important. Attributes that were rated as either very important or extremely important by at least $50 \%$ of respondents included problem analysis, investigation, individual and team work, communication skills, professionalism, ethics and equity, economics and project management, and lifelong learning (Fig. 2). All of the remaining attributes were rated as either very important or extremely important by at least $40 \%$ of respondents. Evidently, survey respondents strongly endorse the 12 graduate attributes that have been identified by CEAB.

It is interesting to compare attributes such as knowledge base in engineering and design with the attribute of communication skills. Approximately $75 \%$ of alumni rated communication skills as extremely important to their current employment. The only other attribute which had a majority of respondents in the "extremely important" category was individual and team work. The ability to work with others in a team setting (which involves communication skills) seems to be a requirement for all engineering employment. 


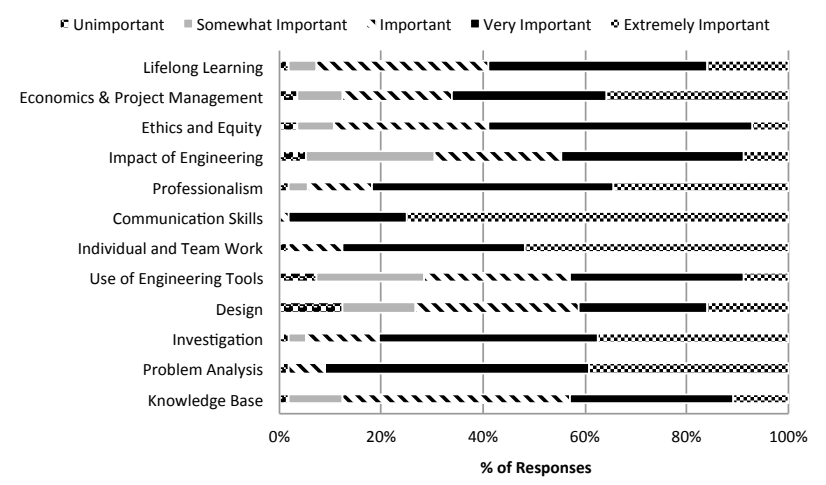

Figure 2. Importance of attributes to respondent's current employment.

\subsection{Level of Preparedness from Biosystems Engineering Program}

Alumni were asked to rate how well the Biosystems Engineering program prepared them in each of the 12 CEAB graduate attributes areas using one of these 5 descriptors: unprepared, somewhat prepared, prepared, well prepared, and extremely prepared. At least $50 \%$ of respondents felt they were either well prepared or extremely prepared for only 5 of 12 attributes (knowledge base for engineering, problem analysis, individual and team work, communication skills, and professionalism). In general, however, there were very few respondents who indicated that they were unprepared in any of the attribute areas based on the engineering education received. The attribute of economics and project management appears to be an area where additional attention may be warranted.

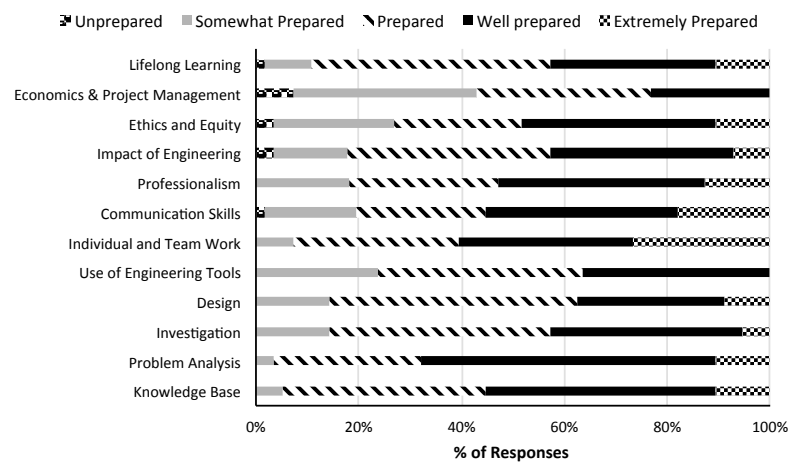

Figure 3. Level of preparedness in attributes received by the Biosystems Engineering program.

\subsection{Competency Level Required by Current Employment}

Alumni were asked to rate the competency level required by their current employment in each of the 12 CEAB graduate attributes areas using one of these 6 descriptors: knowledge, comprehension, application, analysis, synthesis, and evaluation. Virtually all levels of Bloom's taxonomy are represented in the responses for the 12 graduate attributes, although the levels of knowledge and comprehension tend to be a minor contribution for most of the attributes (Fig. 4).

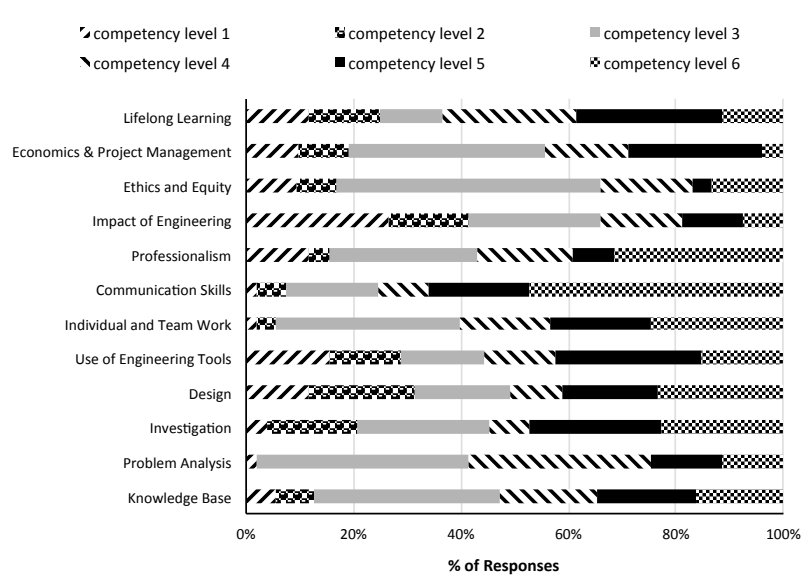

Figure 4. Competency level required of respondent's current employment.

\subsection{Gap Analysis}

Gap analysis is a technique that can be used to detect differences between two levels of performance or achievement. In this scenario, gap analysis can be used to detect differences between level of preparedness and competency level required of current employment. To facilitate this comparison (between the data in Figs. 3 and 4), weighted means were calculated for level of preparedness on each graduate attribute (five-level scale) and competency level required on each graduate attribute (six-level scale). Each weighted average was converted to a ten-level scale to facilitate comparison (Fig. 5).

The gap analysis illustrates the attributes that require more attention. Alumni responded that they observed the greatest negative gap in attribute 7 (communication skills) and positive gap in attribute 9 (impact of engineering on society and the environment). The negative gap indicates that more focus is required in preparation of this attribute in the curriculum because it requires a higher competency level in the workplace than is currently being attained. Conversely, the positive gap suggests that alumni felt over-prepared in this attribute once entering the workplace. 


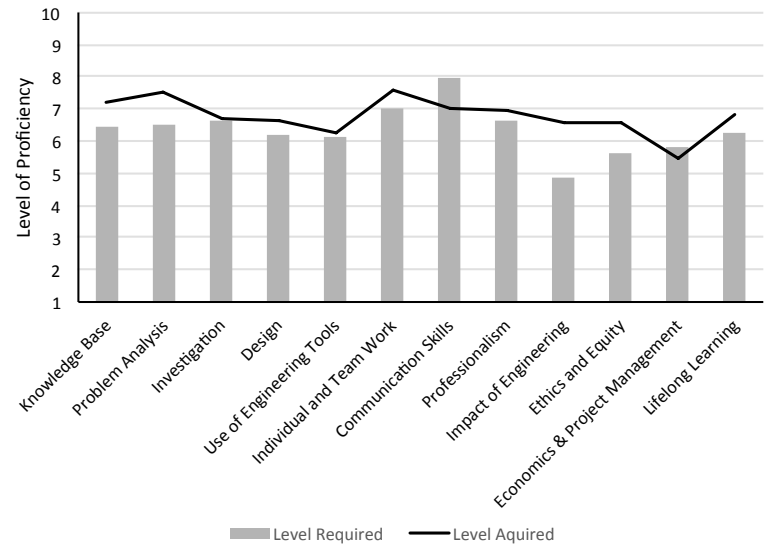

Figure 5. Gap Analysis of level required by employment and level acquired from Biosystems Engineering program in the CEAB attributes.

\subsection{Trend Analysis}

A trend analysis can be used to compare the perception of the importance of each attribute (as expressed by the alumni respondent) with the level of preparedness felt once in the workplace. The trend analysis (Fig. 6) identifies the attributes that are stressed as important in industry in relation to the proficiency levels acquired when in the Biosystems Engineering program. The trend analysis illustrates areas that require attention in order to meet industry focus (i.e., communication skills \& economics and project management). On the other hand, several attributes (i.e., knowledge base for engineering, design, use of engineering tools, and impact of engineering on society and the environment) have been rated as meeting the industry's focus on these attributes.

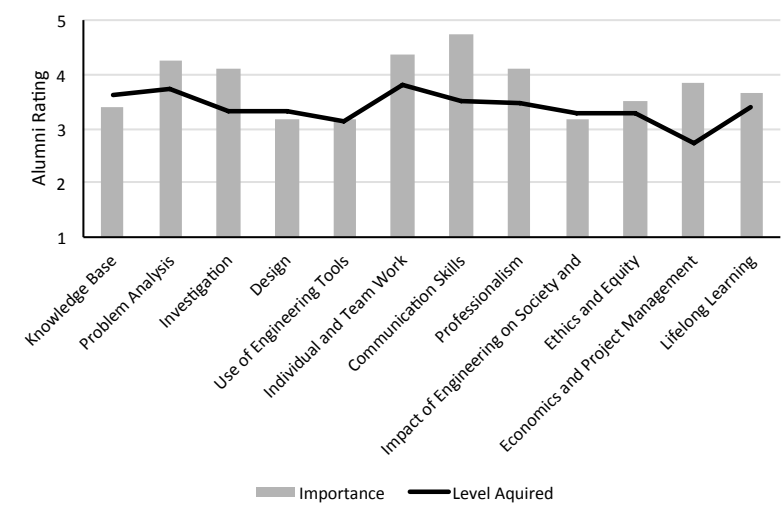

Figure 6. Trend Analysis of importance of attributes in alumni employment in relation to preparedness received through their education.
The participation of student engineers in extracurricular activities is promoted throughout the Biosystems Engineering program. For this reason, analysis was performed to determine how respondents who had pursued these extra-curricular activities rated their preparedness (Fig. 7). This trend analysis illustrates that alumni who participated in co-op rated themselves more prepared in eight of the attributes, but lacking most in preparedness of attribute 11(economics and project management). On the contrary, alumni that had participated in extra-curricular design teams rated themselves as more prepared in only four of the attributes, but lacking in the three attributes associated with interpersonal skills (i.e., individual and teamwork, communication skills, and professionalism).

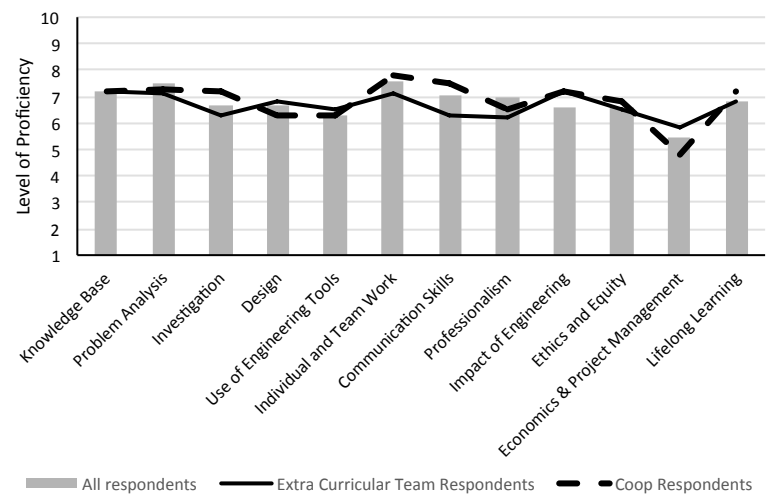

Figure 7. Trend analysis of preparedness as rated by respondents that participated in extra-curricular activities.

Another trend analysis was performed to determine whether graduates of less than five years and graduates of more than five years would find importance in different attributes in the workplace (Fig. 8). Five years since graduation was used as the cut-off to distinguish between those most likely to be still working as an engineer-intraining and those who had passed that milestone in their career development. Even with this distinction, most alumni reported similar levels of importance for all of the attributes.

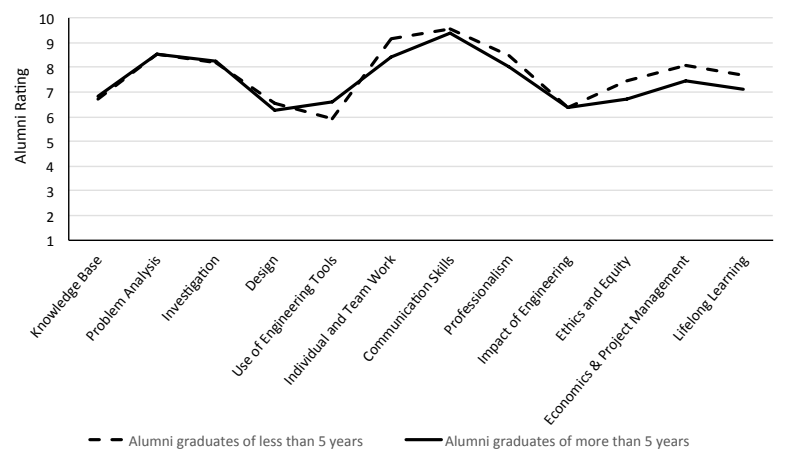

Figure 8. Trend analysis of alumni greater than and less than 5 years. 


\section{CONCLUSIONS}

The Department of Biosystems Engineering conducted a survey of its alumni with the intent of gathering indirect evidence of performance on the 12 CEAB graduate attributes. Over $27 \%$ of alumni contacted provided feedback on i) importance of each attribute to current employment, ii) level of preparedness from the Biosystems Engineering program in the area of each attribute, and iii) competency level required in each attribute for their current employment. A large number of respondents $(39 \%)$ were within 5 years of graduation yielding good feedback on the current Biosystems Engineering curriculum. The alumni respondents rated all $12 \mathrm{CEAB}$ graduate attributes as being important to their current employment. Although there were almost nil responses of alumni being unprepared for their current employment based on the education that they received from the Biosystems Engineering program, there were only a small proportion of respondents who rated themselves as being "extremely prepared" for their employment. The results indicate there is opportunity for improvement. Upon further gap and trend analysis, it was identified that i) communication skills and ii) economics and project management are two attributes where further attention in the curriculum may be warranted. Interestingly, a positive gap was identified for the attribute of impact of engineering on society and the environment. One interpretation is that less attention could be devoted to this attribute within the Biosystems Engineering program. Alternatively, a second interpretation is that this attribute is currently being undervalued in industry. Perhaps the university can play a leadership role by continuing to graduate engineers with values related to this attribute.

\section{References}

[1] Engineers Canada, Accreditation Criteria and Procedures 2008. Ottawa, ON: Canadian Engineering Accreditation Board (CEAB), 2008. Available as of September 30, 2013 from: http://www.engineerscanada.ca/e/files/report ceab 08 txt only.pdf.

[2] D.D. Nulty, "The adequacy of response rates to online and paper surveys: what can be done?" Assessment \& Evaluation in Higher Education, vol. 33, no. 3, pp. 301-314, 2008. 